\title{
Effect of the Glycerol and Lignin Extracted from Piassava Fiber in Cassava and Corn Starch Films
}

\author{
Cleidiene Souza de Miranda ${ }^{a *}$, Marina Santos Ferreira ${ }^{a}$,Mariana Tibo Magalhães ${ }^{a}$, \\ Ana Paula Bispo Gonçalves ${ }^{a}$, Jamerson Carneiro de Oliveira ${ }^{a}$, \\ Danilo Hansen Guimarães ${ }^{a}$, Nadia Mamede José $e^{a}$

\begin{abstract}
a Programa de Pós-graduação de Engenharia Química, Instituto de Química, Universidade Federal da Bahia-UFBA, Campus de Ondina, CEP 40170-290, Salvador, BA, Brazil
\end{abstract}

Received: December 15, 2014; Revised: August 30, 2015

\begin{abstract}
Several alternatives have been considered to minimize the environmental impact caused by conventional polymers. This study aims to evaluate the chemical, mechanical and morphological properties of flexible thermoplastic films of cassava and corn starch, using glycerol and lignin as plasticizers and reinforcement. The films were produced through casting. It was observed that the presence of lignin effectively increased the maximum stress and the elastic modulus by about of $840 \%$ and $4200 \%$, respectively, when comparing to the film containing only glycerol. In addition, lignin improved thermal properties, modified some structural properties and made the surface of the material rougher.
\end{abstract}

Keywords: starch, lignin, glycerol, properties

\section{Introducion}

Lignocellulosic fibers are excellent raw materials for the polymers and composites field. This can be proven by the high number of patents, papers and products already marketed ${ }^{1-6}$. Piassava fibers are extracted from the palm tree Attalea funifera Martius. During manufacturing of the fiber, wastes are created and their use is of particular interest due to their good chemical and mechanical properties. Furthermore, the state of Bahia, Brazil, is responsible for $90 \%$ of the production of piassava wastes and their use as reinforcement in polymer matrices has already been performed, adding them a new commercial value $e^{7-8}$.

The study of the fiber fractionation process is of great need, because it enables the use of isolated components from plant fibers in specific applications 9 . The lignin is a polyphenolic, amorphous, hydrophobic, low-density and abrasive material. It acts as cement, stiffener agent, water proofing material and protector against microorganisms in plant fibers. Due to the phenolic nature, lignin has interesting qualities for replacing inorganic fillers. It provides biodegradability and thermoplastic characteristics to polymeric materials, while increasing their oxidation and thermal resistance ${ }^{9-10}$.

Incorporation of lignin in starch matrixes modifies the physical and chemical properties of the matrixes. Some results from literature show an increase in thermal resistance, significant reduction in steam permeability and water activity, structural modification of starch and an increase in strength and stiffness with a decrease in elongation ${ }^{11-16}$.

Due to its good compatibility, glycerol is widely used as plasticizer for starch films. Additionally, glycerol improves processing and the flexibility of films $\mathrm{s}^{17,18}$. This work establishes

*e-mail: cleidienesm@gmail.com biotechnological strategies for the use of purified glycerol from biodiesel production with the intention to open future perspectives for plastic industries ${ }^{8,18,19}$.

This study aims to evaluate the chemical, mechanical and morphological properties of flexible thermoplastic films of cassava and corn starch, using glycerol and lignin as plasticizers and reinforcement.

\section{Material and Methods}

\subsection{Materials}

Corn and cassava starch were donated by Cargill Agrícola S.A. (Porto Ferreira, Brazil). Piassava fiber wastes (Attalea funifera Martius) came from Ilhéus (Bahia, Brasil). The other reagents employed in this study were: sulfuric acid (95.0-98.0 wt.\%, Vetec, P.A.), sodium hydroxide (Vetec) and glycerol (Vetec).

\subsection{Methods}

\subsubsection{Extraction of lignin}

Piassava fiber wastes were treated for $2 \mathrm{~h}$ in $5 \%$ alkali solution at $80^{\circ} \mathrm{C}$. Lignin was precipitated from the liquor with concentrated sulfuric acid, centrifuged, washed with distilled water and dried in an oven at $50^{\circ} \mathrm{C}$.

\subsubsection{Biocomposites preparation}

Thermoplastic starch, without lignin, was processed by casting a mixture of corn or cassava starch $(10 \mathrm{~g})$, glycerol $(5 \mathrm{~g})$ and distilled water (185 g) and was coded FSCO or $\mathrm{FSCA}^{20}$. Sample films, with lignin, were prepared by casting a mixture of starch (10 g), glycerol and lignin 
(5 g total - varying: 1, 2, 3 or $4 \mathrm{~g}$ of lignin) and $185 \mathrm{~g}$ of distilled water. A series of corn starch plasticized with glycerol and lignin was coded as FSCO1L, FSCO2L, FSCO3L and FSCO4L. A series of cassava starch plasticized with glycerol and lignin was coded as FSCA1L, FSCA2L, FSCA3L and FSCA4L. The samples were heated to $70-80{ }^{\circ} \mathrm{C}$ and dried at $40{ }^{\circ} \mathrm{C}$ for $24 \mathrm{~h}$. Samples were stored at $25{ }^{\circ} \mathrm{C}$ and $58 \%$ relative humidity $(\mathrm{RH})$ for 2 days prior analysis. Thicknesses of the films were between $0.11-0.15 \pm 0.03$.

\subsection{Characterization}

Thermal stability of samples was determined using Shimadzu TGA-50 equipment. The analysis conditions were: a nitrogen atmosphere with flow $50 \mathrm{~mL} \mathrm{~min}^{-1}$, heating rate of $20{ }^{\circ} \mathrm{C} \mathrm{min}-1$ and temperature range from 25 to $1000{ }^{\circ} \mathrm{C}$. The diffractograms were obtained on X-ray diffractometer, Shimadzu model XRD- 6000 with angles $2 \theta$ between 5 and $80^{\circ}$. Their crystallinity index was estimated by the height ratio of the diffraction peak (B-type at $2 \theta=17^{\circ}$ and $\mathrm{V}_{\mathrm{H}}$-type at



(a)

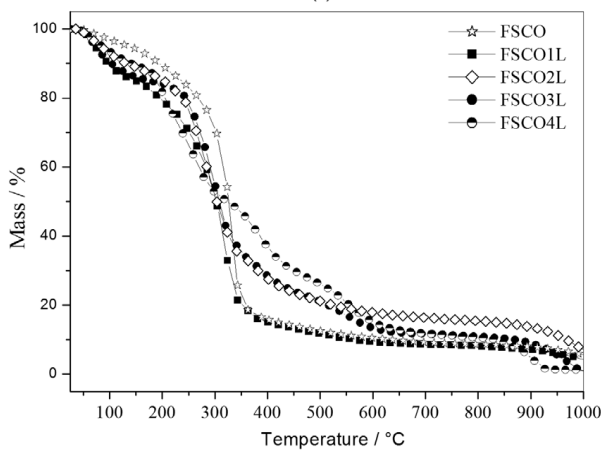

(c)

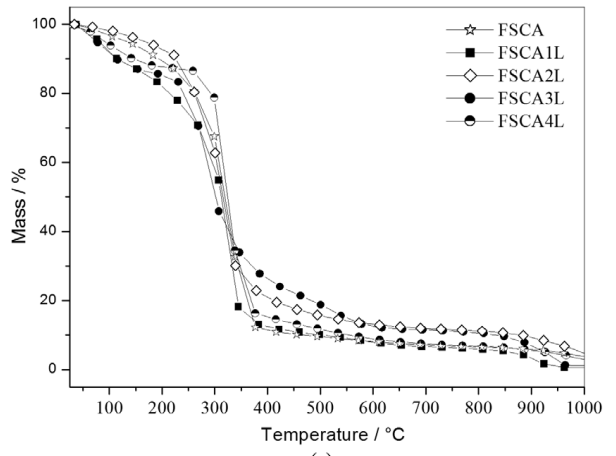

(e)
$2 \theta=20^{\circ}$ ), as reported in literature ${ }^{21-23}$. Scanning Electron Microscope JEOL 6390LV was used to analyze the surface. All samples were gold sputter coated in an argon atmosphere. Mechanical testing in tensile mode were obtained using an Emic Universal Testing Instrument (Model DL2000), operated as specified in the ASTM standard method D882-00 ${ }^{[24]}$. Film strips of $8 \mathrm{~cm} \times 2.5 \mathrm{~cm}$ (length $\times$ width) were cut from each preconditioned sample and placed between the grips of the machine. The initial grip separation and crosshead speed were set to $50 \mathrm{~mm}$ and $12.5 \mathrm{~mm} / \mathrm{min}$, respectively. At least 10 replicates of each specimen were averaged together. The Tukey test was used to evaluate average differences (at a $95 \%$ confidence interval).

\section{Results and Discussion}

The thermal behavior of the samples is shown in Figure 1. According to literature, lignin decomposes between $90-800{ }^{\circ} \mathrm{C}^{7}$, but with slow mass loss due to its complex structure. By analyzing its DTG curve two events can be

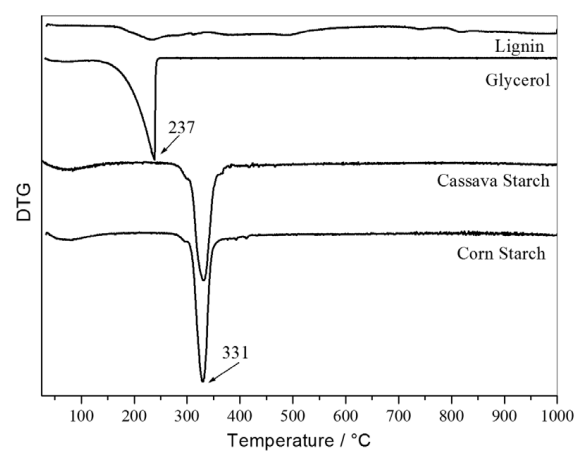

(b)

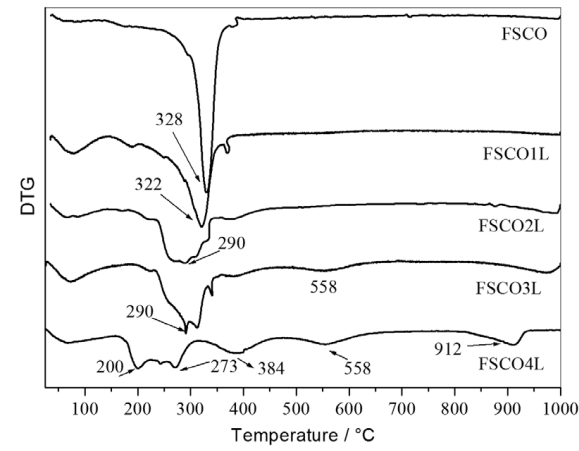

(d)

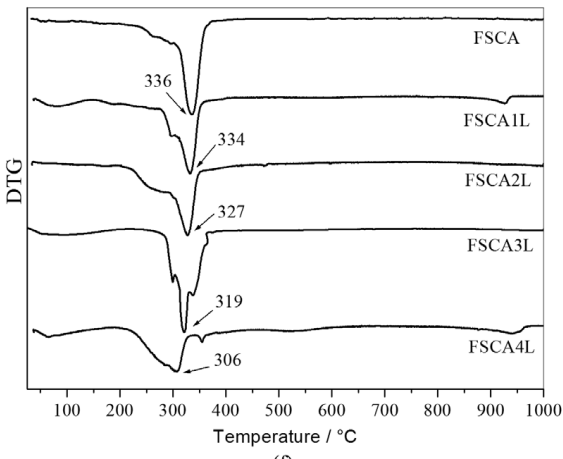

(f)

Figure 1. TGA and DTG curves of the precursors (a)/(b) the films of corn (c)/(d) and cassava (e)/(f) starch. 
observed: the first related to the degradation of hemicelluloses, waste from the extraction process, and the second related to the maximum degradation rate of lignin. Also, two events were observed to starch: the first referring to the humidity and the second, with a maximum around $331^{\circ} \mathrm{C}$, related to its degradation. Glycerol showed the maximum degradation temperature around $237^{\circ} \mathrm{C}^{15,16,22}$, according to Figure $1 \mathrm{~b}$.

By analyzing the thermal behavior of the films, three events were observed. In the starch film plasticized with glycerol (FSCO and FSCA), the first event refers to humidity, the second event relates to the degradation of glycerol and the third event is related to the degradation of starch. By adding lignin it was observed an increase in thermal stability of the material and displacement of the third event to a maximum temperature less than the degradation rate. Thus, one may infer a good compatibility between starch and lignin. Beyond $3 \mathrm{~g}$ of lignin, the presence of residual lignin in the film was noticed, especially in FSCO4L series.

XRD diffractograms of the films and precursor starches are shown in Figure 2. A decrease in starch crystallinity can be observed when lignin is incorporated. This result was more noticeable for FSCA4L series, which showed a profile of a total amorphous material. Since lignin is an amorphous polymer, this change in crystallinity was expected. Cassava starch presented a C-type crystallinity and corn starch presented an A-type ${ }^{22,23}$.

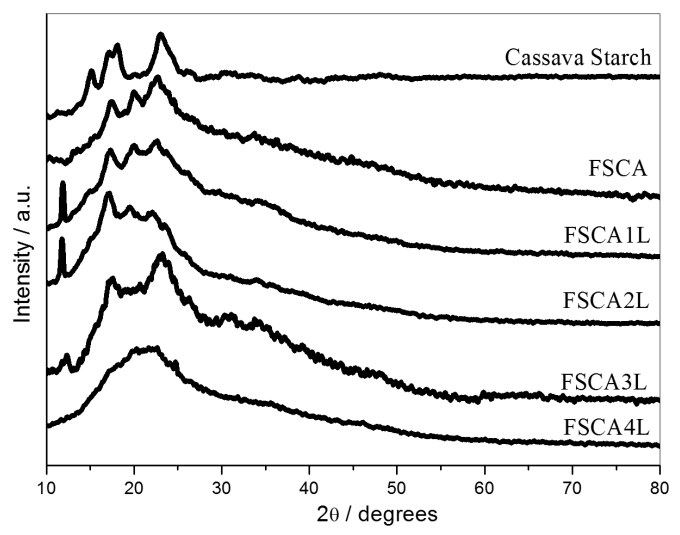

(a)
Starch films displayed a diffraction peak around $2 \theta=17^{\circ}$ that is characteristic of amylopectin recrystallization (B-type crystallization). Besides, a processing-induced crystallization occurs, with recrystallization of amylose's single helical structure during cooling. This crystallinity is known as $\mathrm{V}_{\mathrm{H}}$-type and it is mainly characterized by the intense peak at $2 \theta=20^{\circ}$. The $\mathrm{V}_{\mathrm{H}}$-type consists of amylose recrystallization induced by complex-forming agents such as glycerol ${ }^{22,23}$. By analyzing the crystallinity indexes values of the films, Table 1 , it is possible to observe that, with addition of lignin, a reduction of the index related to the $\mathrm{V}_{\mathrm{H}}$-type peak occurs. This peak disappears for the samples FSCA3L, FSCA4L and FSCO4L. To cassava starch films, it can be observed a decrease of the index related to B-type crystallinity and disappearance of the characteristic peak to the sample FSCA4L. However, for corn starch films, an increase in B-type crystallinity index was observed to the samples FSCO3L and FSCO4L. According to the literature ${ }^{25,26}$, partial compatibility between starch and lignin can be attributed to strong interactions between the phenolic groups in lignin and the amorphous region of starch, where amylose is more available.

By analyzing the morphology of the materials, Figure 3, it is possible to observe that the films were more homogeneous when plasticized only with glycerol. When lignin was added the surface became rougher, this can be readily seen for the cassava starch series. This result corroborates the ones

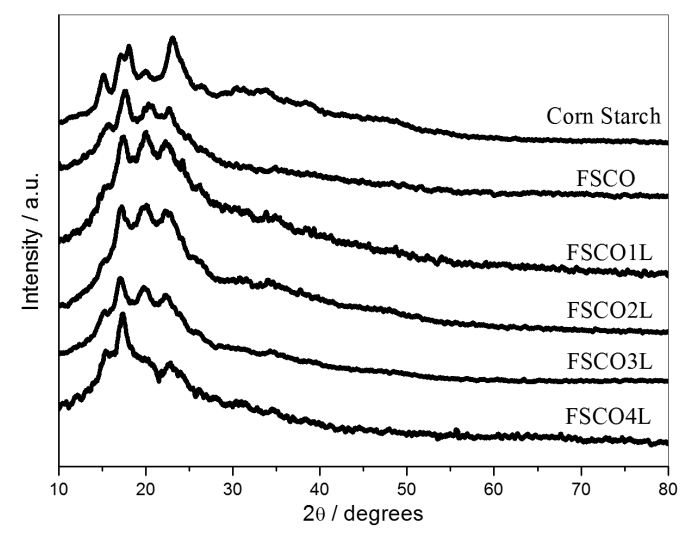

(b)

Figure 2. XRD diffractograms of the films of cassava (a) and corn (b) starch.

Table 1. Elasticity modulus values, maximum stress, specific deformation and crystallinity index for the films.

\begin{tabular}{lrcccc}
\hline Sample & $\boldsymbol{\sigma}(\mathbf{M P a})$ & $\mathbf{E}(\mathbf{M P a})$ & $\boldsymbol{\varepsilon}(\mathbf{\%})$ & $\mathbf{I}_{\mathbf{C}} \mathbf{B}-\mathbf{T y p e}$ & $\mathbf{I}_{\mathbf{C}} \mathbf{V}_{\mathbf{H}^{-T y p e}}$ \\
\hline FSCA & $2.144 \pm 0.193^{\mathrm{c}}$ & $21.600 \pm 4.519^{\mathrm{c}}$ & $50.967 \pm 4.421^{\mathrm{a}}$ & 0.26 & 0.34 \\
FSCA1L & $2.207 \pm 0.320^{\mathrm{c}}$ & $34.200 \pm 10.614^{\mathrm{c}}$ & $50.322 \pm 4.082^{\mathrm{a}}$ & 0.22 & 0.27 \\
FSCA2L & $2.415 \pm 0.599^{\mathrm{c}}$ & $75.200 \pm 13.490^{\mathrm{c}}$ & $43.017 \pm 3.651^{\mathrm{b}}$ & 0.26 & 0.10 \\
FSCA3L & $5.022 \pm 0.128^{\mathrm{b}}$ & $240.900 \pm 16.668^{\mathrm{b}}$ & $14.406 \pm 3.841^{\mathrm{c}}$ & 0.15 & - \\
FSCA4L & $20.153 \pm 1.854^{\mathrm{a}}$ & $930.100 \pm 96.479^{\mathrm{a}}$ & $9.865 \pm 2.844^{\mathrm{c}}$ & - & - \\
FSCO & $1.717 \pm 0.087^{\mathrm{c}}$ & $12.100 \pm 0.944^{\mathrm{c}}$ & $47.278 \pm 2.994^{\mathrm{a}}$ & 0.39 & 0.27 \\
FSCO1L & $3.132 \pm 0.246^{\mathrm{c}}$ & $66.600 \pm 11.872^{\mathrm{c}}$ & $33.121 \pm 2.556^{\mathrm{b}}$ & 0.19 & 0.23 \\
FSCO2L & $3.198 \pm 0.245^{\mathrm{c}}$ & $69.400 \pm 13.028^{\mathrm{c}}$ & $28.967 \pm 5.015^{\mathrm{b}}$ & 0.19 & 0.22 \\
FSCO3L & $5.839 \pm 0.865^{\mathrm{b}}$ & $254.000 \pm 59.760^{\mathrm{b}}$ & $6.622 \pm 2.085^{\mathrm{c}}$ & 0.33 & 0.23 \\
FSCO4L & $14.293 \pm 1.883^{\mathrm{a}}$ & $673.500 \pm 53.203^{\mathrm{a}}$ & $3.239 \pm 0.293^{\mathrm{c}}$ & 0.43 & - \\
\hline
\end{tabular}

Experimental values with the same letter and in the same column mean that they are not significantly different $(\mathrm{P}>0.05)$. 


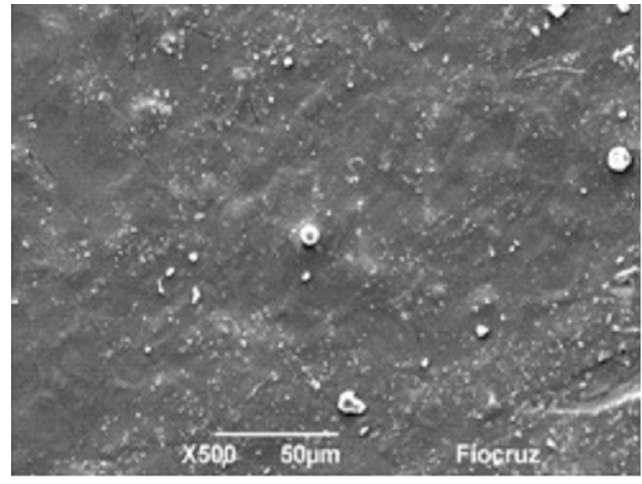

(a)

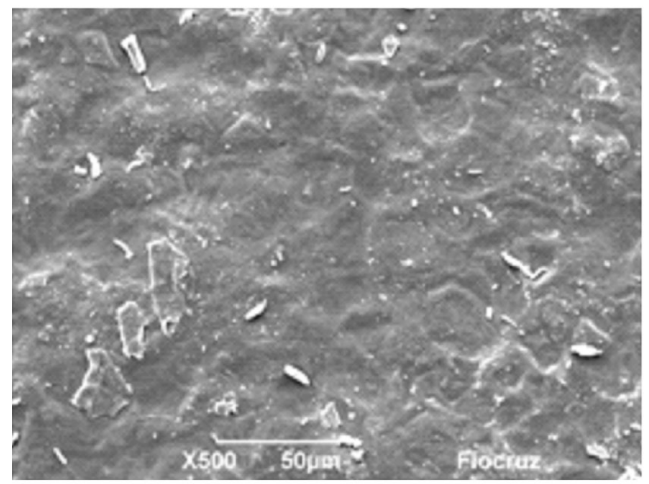

(c)

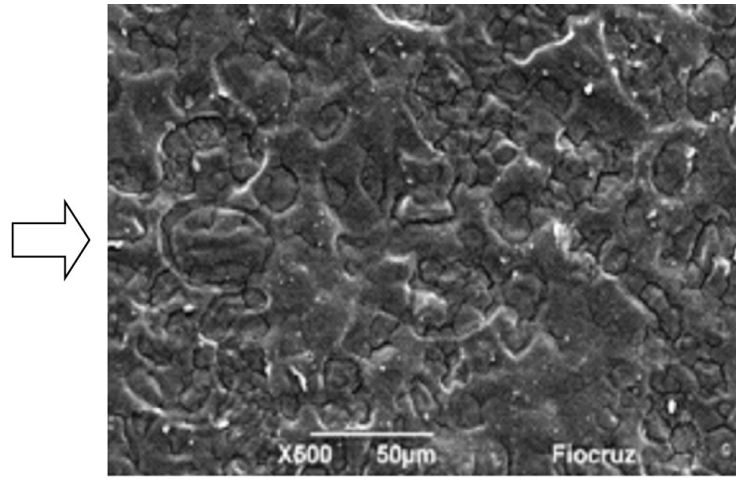

(b)

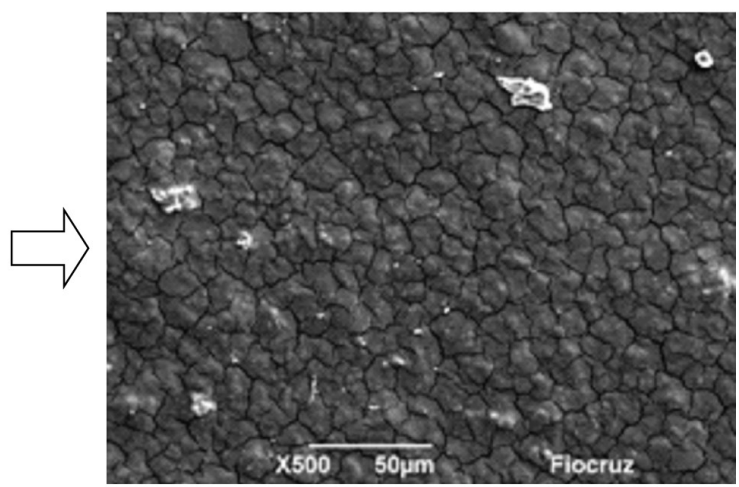

(d)

Figure 3. Scanning electron micrographs of the surface in 500x FSCA (a), FSCA2L (b), FSCO (c) and FSCO2L (d).

obtained by TG and XRD, wherein the lignin interacted more easily with the cassava starch than corn.

Figure 4 illustrates the behavior of tension as a function of strain. It was observed that starch plasticized with glycerol had a high deformation and the addition of lignin promoted a change in the profile, producing more rigid films.

Table 1 shows the ${ }^{24}$ mechanical properties values. By comparing the results of the samples FSCA and FSCO to the samples FSCA4L and FSCO4L, an increase in the materials strength by 840 and $730 \%$, respectively, was observed. Also, an increase in elastic modulus by about 4200 and $5400 \%$ and a decrease of the elongation at maximum force by 80 and $90 \%$, respectively, were observed. Therefore, it can be inferred that higher concentrations of lignin increases ability for forming a rigid continuous network of the precursors, which are connected to each other through hydrogen bonding. This hinders the elongation of the chains and increases stiffness of the films due to the good interaction between starch, lignin and glycerol. For FSCO3L and FSCO4L samples, these results can also be related to the increase in B-type crystallinity (crystallization of amylopectin), discussed earlier in the XRD diffraction patterns, which can lead to an increase in stress at break and decrease in elongation in starch films ${ }^{22-25}$.

\section{Conclusions}

It was observed that lignin incorporation in starch films improved thermal and mechanical properties, modified structural properties and made the materials surface rougher.

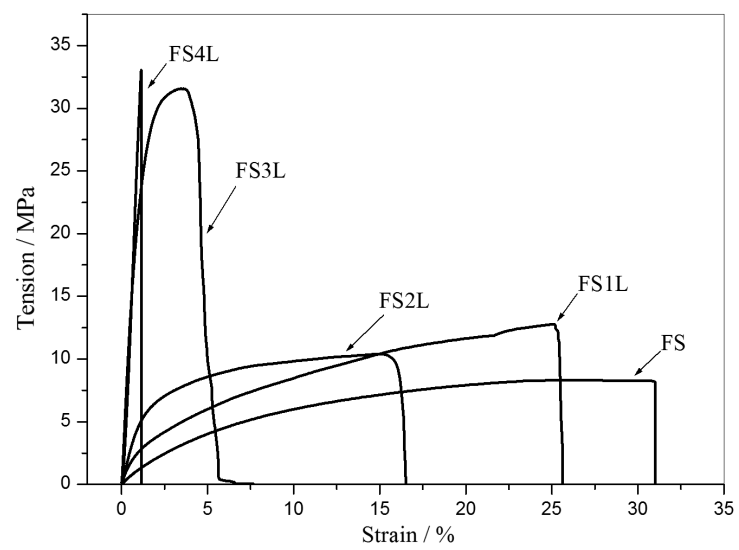

Figure 4. Illustration of the tension $\times$ strain behavior of the films.

Cassava starch showed better results in comparison to corn starch due to better compatibility with lignin. Therefore, the films properties are directly related to the degree of lignin association with starch and glycerol.

\section{Acknowledgements}

The authors thank to FAPESB (Foundation for Research of State of Bahia) for financial support and scholarship and Oswaldo Cruz Foundation of Bahia for the analysis of scanning electron microscopy. Miranda CS thanks CAPES for scholarship. 


\section{References}

1. Catto AL, Stefani BV, Ribeiro VF and Santana RMC. Influence of Coupling agent in compatibility of post-consumer HDPE in thermoplastic composites reinforced with eucalyptus fiber. Materials Research. 2014; 17(Suppl 1):203-209. http://dx.doi. org/10.1590/S1516-14392014005000036.

2. Chianelli-Junior R, Reis JML, Cardoso JL and Castro PF. Mechanical characterization of sisal fiber-reinforced recycled HDPE composites. Materials Research. 2013; 16(6):1393-1397. http://dx.doi.org/10.1590/S1516-14392013005000128.

3. Gelfuso MV, Thomazini D, Souza JCS and Lima JJ Jr. Vibrational analysis of coconut fiber-PP composites. Materials Research. 2014; 17(2):367-372. http://dx.doi.org/10.1590/ S1516-14392013005000200.

4. Borba PM, Tedesco A and Lenz DM. Effect of reinforcement nanoparticles addition on mechanical properties of SBS/Curauá fiber composites. Materials Research. 2014; 17(2):412-419. http://dx.doi.org/10.1590/S1516-14392013005000203.

5. Gelfuso MV, Silva PVG and Thomazini D. Polypropylene matrix composites reinforced with coconut fibers. Materials Research. 2011; 14(3):360-365. http://dx.doi.org/10.1590/ S1516-14392011005000056.

6. Castro CDPC, Dias CGBT and Faria JAF. Production and evaluation of recycled polymers from açaí fibers. Materials Research. 2010; 13(2):159-163. http://dx.doi.org/10.1590/ S1516-14392010000200007.

7. Miranda CS. Sintese e caracterização de poliésteres e compósitos reforçados com fibra de piaçava. [Dissertation]. Salvador: Federal University of Bahia; 2011.

8. Miranda CS, Fiuza RP, Oliveira J, Carvalho RF, Guimarães DH and José NM. Thermal, mechanical and morphological properties of composites developed from glycerol and dicarboxylic acids reinforced with Piassava fiber. Macromolecular Symposia. 2012; 319(1):74-82. http://dx.doi.org/10.1002/masy.201100229.

9. Silva R, Haraguchi SK, Muniz EC and Rubira AF. Aplicações de fibras lignocelulósicas na química de polímeros e em compósitos. Quimica Nova. 2009; 32(3):661-671. http://dx.doi. org/10.1590/S0100-40422009000300010.

10. Poletto $M$ and Zattera AJ. Materials produced from plant biomass. Part III: degradation kinetics and hydrogen bonding in lignin. Materials Research. 2013; 16(5):1065-1070. http:// dx.doi.org/10.1590/S1516-14392013005000112.

11. Kaewtatip K and Thongmee J. Effect of kraft lignin and esterified lignin on the properties of thermoplastic starch. Materials \& Design. 2013; 49:701-704. http://dx.doi.org/10.1016/j. matdes.2013.02.010.

12. Bhat R, Abdullah N, Din RH and Tay GS. Producing novel sago starch based food packaging films by incorporating lignin isolated from oil palm black liquor waste. Journal of Food Engineering. 2013; 119(4):707-713. http://dx.doi.org/10.1016/j. jfoodeng.2013.06.043.

13. Spiridon I, Teaca CA and Bodirlau R. Preparation and characterization of adipic acid-modified starch microparticles/ plasticized starch composite films reinforced by lignin. Journal of Materials Science. 2011; 46(10):3241-3251. http://dx.doi. org/10.1007/s10853-010-5210-0.
14. Stevens ES, Klamczynski A and Glenn GM. Starch-lignin foams. Express Polymer Letters. 2010; 4(5):311-320. http:// dx.doi.org/10.3144/expresspolymlett.2010.39.

15. Miranda CS, Ferreira MS, Magalhães MT, Santos WJ, Oliveira JC, Silva JBA, et al. Mechanical, thermal and barrier properties of starch-based films plasticized with glycerol and lignin and reinforced with cellulose nanocrystals. Materials Today: Proceedings. 2015; 2(1):63-69. http://dx.doi.org/10.1016/j. matpr.2015.04.009.

16. Miranda CS, Ferreira MS, Magalhães MT, Bispo APG, Oliveira JC, Silva JBA, et al. Starch-based films plasticized with glycerol and lignin from piassava fiber reinfORCED with nanocrystals from eucalyptus. Materials Today: Proceedings. 2015; 2(1):134140. http://dx.doi.org/10.1016/j.matpr.2015.04.038.

17. Brioude MM, Guimarães DH, Fiúza RP, Prado LASA, Boaventura JS and José NM. Synthesis and characterization of aliphatic polyesters from glycerol, by-product of biodiesel production, and adipic acid. Materials Research. 2007; 10(4):335-339. http://dx.doi.org/10.1590/S1516-14392007000400003.

18. Guimarães DH, Brioude MM, Fiúza RP, Prado LASA, Boaventura JS and José NM. Synthesis and characterization of polyesters derived from glycerol and phthalic acid. Materials Research. 2007; 10(3):257-260. http://dx.doi.org/10.1590/ S1516-14392007000300007.

19. Corradini E, Carvalho AJF, Curvelo AAS, Agnelli JAM and Mattoso LHC. Preparation and characterization of thermoplastic starch/zein blends. Materials Research. 2007; 10(3):227-231. http://dx.doi.org/10.1590/S1516-14392007000300002.

20. García NL, Ribba L, Dufresne A, Aranguren M and Goyanes S. Effect of glycerol on the morphology of nanocomposites made from thermoplastic starch and starch nanocrystals. Carbohydrate Polymers. 2011; 84(1):203-210. http://dx.doi. org/10.1016/j.carbpol.2010.11.024.

21. Hulleman SHD, Kalisvaart MG, Janssen FHP, Feil H and Vliegenthart JFG. Origins of B-type crystallinity in glycerolplasticised, compression-mouldedpotato starches. Carbohydrate Polymers. 1999; 39(4):351-360. http://dx.doi.org/10.1016/ S0144-8617(99)00024-7.

22. Oliveira JC. Sintese e caracterização de nanocompósitos polímericos reforçados com whiskers de celulose da fibra de licuri. [Dissertation]. Salvador: Federal University of Bahia; 2015 .

23. Teixeira EM, Pasquini D, Curvelo AAS, Corradini E, Belgacem $\mathrm{MN}$ and Dufresne A. Cassava bagasse cellulose nanofibrils reinforced thermoplastic cassava starch. Carbohydrate Polymers. 2009; 78(3):422-431. http://dx.doi.org/10.1016/j. carbpol.2009.04.034.

24. American Society for Testing and Materials - ASTM. Annual book of ASTM Standards. West Conshohocken: 2000. 1454 p.

25. Baumberger S, Lapierre $\mathrm{C}$ and Monties B. Utilization of pine kraft lignin in starch composites: impact of structural heterogeneity. Journal of Agricultural and Food Chemistry. 1998; 46(6):2234-2240. http://dx.doi.org/10.1021/jf971067h.

26. Baumberger S, Lapierre C, Monties B and Valle GD. Use of kraft lignin as filler for starch films. Polymer Degradation \& Stability. 1998; 59(1-3):213-211. http://dx.doi.org/10.1016/ S0141-3910(97)00193-6. 